\title{
Salivary Resistin and TNF- $\alpha$ Levels in Different Periodontal Diseases
}

\author{
Farklı Periodontal Hastalıklarda Tükürük Resistin ve TNF- $\alpha$ Seviyeleri \\ Beral AFACAN', Zeynep Pınar KELEŞ YÜCEL² ${ }^{2}$ Çiğdem YENISEY³, Nejat NiZAM, Gülnur EMINGí \\ ${ }^{1}$ Department of Periodontology, School of Dentistry, Aydın Adnan Menderes University, Aydın, Turkey. \\ 2 Department of Periodontology, School of Dentistry, Giresun University, Giresun, Turkey. \\ ${ }^{3}$ Department of Biochemistry, School of Medicine, Aydın Adnan Menderes University, Aydın, Turkey \\ ${ }^{4}$ Department of Periodontology, School of Dentistry, İzmir Ege University, İzmir, Turkey.
}

Atıf/Citation: Afacan, B., Keleş, Yücel, Z.P., Yenisey, Ç., Nizam, N. \& Emingil, G. (2019). Salivary Resistin and TNF-a Levels in Different Periodontal Diseases. Ege Üniversitesi Diş Hekimliği Fakültesi Dergisi, 40(3), 177-184.

\begin{abstract}
Objective: Resistin is a cytokine involved in insulin resistance, inflammation and immunity. The relationship of resistin with tumor necrosis factor (TNF)- $\alpha$, one of the key cytokines of periodontal inflammation, is bidirectional. This study aimed to evaluate salivary resistin and TNF- $\alpha$ levels in different periodontal diseases.

Methods and Materials: Saliva samples were collected from 20 generalized aggressive periodontitis (G-AgP), 20 chronic periodontitis (CP), 20 gingivitis patients and 20 periodontally healthy individuals. Probing pocket depth (PD), clinical attachment levels (CAL), papillary bleeding index $(\mathrm{PBI})$ and plaque index were recorded. Salivary resistin and TNF- $\alpha$ levels were analyzed by enzyme-linked immunosorbent assay. Inter-group comparison was performed by the Kruskal-Wallis test and Dunn's post-hoc test.

Results: G-AgP, CP and gingivitis groups exhibited higher salivary resistin and TNF- $\alpha$ levels compared to the periodontally healthy controls, however, this did not reach to statistical significance $(p>0.05)$. Although both periodontitis groups had significantly higher mean PD, CAL and PBI scores compared to gingivitis group $(p<0.0001)$, salivary cytokine levels were similar in these groups $(p>0.05)$.

Conclusion: Within the limits of the present findings, salivary resistin and TNF-a levels could not differentiate periodontal disease from health. Further investigations with larger sample size are needed to elucidate the potential relationship salivary levels of these cytokines with periodontal inflammation.
\end{abstract}

Key words: Periodontitis, gingivitis, inflammation, saliva, cytokine

\section{ÖZ}

Amaç: Resistin, insülin direnci, enflamasyon ve immünite ile ilişkili bir sitokindir. Resistinin, periodontal enflamasyonun ana sitokinlerinden biri olan tümör nekroz faktör (TNF)- $\alpha$ ile olan ilişkisi çift yönlüdür. Bu çalışma farklı periodontal hastalıklarda tükürük resistin ve TNF- $\alpha$ seviyelerini değerlendirmeyi amaçlamaktadır.

Yöntem: Tükürük örnekleri, 20 yaygın agresif periodontitis (Y-AgP), 20 kronik periodontitis (KP), 20 gingivitis hastası ile 20 periodontal sağlıklı bireyden elde edildi. Sondalanan cep derinliği (SCD), klinik ataşman seviyesi (KAS), papil kanama indeksi (PKI) ve plak indeksi değerleri kaydedildi. Tükürük resistin ve TNF-a seviyeleri enzim bağlı immunosorbent yöntemi ile analiz edildi. Gruplar arası karşılaştırmalar, Kruskal-Wallis testi ve Dunn post-hoc testi ile yapıldı.

Bulgular: Y-AgP, KP ve gingivitis gruplarının tükürük resistin ve TNF-a seviyeleri, periodontal sağlıklı bireylerden yüksekti ancak bu fark istatistiksel olarak anlamlı bulunmadı ( $p>0.05)$. Her iki periodontitis grubunun SCD, KAS ve PKI ortalama değerleri, gingivitis grubundan anlamlı yüksek olmasına rağmen $(p<0.0001)$, sitokinlerin tükürükteki seviyeleri gruplar arasında benzerdi $(p>0.05)$.

Sonuç: Bu çalışmanın sınırlamaları dahilinde, tükürük resistin ve TNF- $\alpha$ seviyeleri periodontal hastalığı, periodontal sağlıktan ayıramamıştır. Bu sitokinlerin tükürükteki seviyelerinin periodontal enflamasyon ile olan olası ilişkisini aydınlatmak için daha geniş örneklem büyüklüğüne sahip ileri çalışmalara ihtiyaç vardır.

Key words: Periodontitis, gingivitis, enflamasyon, tükürük, sitokin 


\section{Introduction}

The periodontal disease is a low-grade chronic infection caused by predominantly Gram-negative anaerobic pathogens located in subgingival biofilm. ${ }^{1}$ The host responds to microbial attack by producing an inflammatory cell infiltrate within the tissues adjacent to periodontal pocket. ${ }^{1,2}$ A variety of inflammatory mediators such as cytokines, chemokines, and proteases are secreted by infiltrating immune and inflammatory cells in diseased periodontal tissues. ${ }^{2}$ There is a substantial evidence to support the association of the local and systemic levels of these inflammatory molecules with the clinical and radiographical features of periodontal disease including gingival inflammation, pocket formation, connective tissue attachment and alveolar bone loss., ${ }^{2,3}$

Resistin was first described as an adipokine involved in insulin resistance and diabetes in obese mice. ${ }^{4}$ Evidence show that resistin is expressed by immunoinflammatory cells, in particular monocytes/macrophages, rather than adipocytes in humans. ${ }^{5}$ It stimulates the secretion of proinflammatory cytokines such as tumor necrosis factor (TNF)- $\alpha$ and interleukin (IL)-6., ${ }^{4,6}$ Resistin also regulates matrix remodeling and osteoclast differentiation by up-regulating matrix metalloproteinases and cellular adhesion molecules. ${ }^{5}$ Collectively, it has been suggested that resistin plays a role in the modulation of inflammatory response. ${ }^{4-6}$ Serum and synovial fluid levels of resistin has been shown to be elevated in various chronic inflammatory conditions such as rheumatoid arthritis, coronary heart diseases, and chronic kidney diseases. ${ }^{5}$ Furugen et al. ${ }^{7}$ reported that increased serum resistin levels were associated with periodontal condition in elderly Japanese people. Hiroshima et al. ${ }^{8}$ and Gokhale et al. ${ }^{9}$ revealed that GCF resistin levels in patients with periodontitis or diabetes mellitus related-periodontitis were significantly higher than that of systemically and periodontally healthy individuals. However, the exact role of resistin in inflammatory periodontal disease is still not clear.

Saliva, a unique oral fluid, has attracted attention as a diagnostic medium because it is relatively easy to collect and contains GCF from the periodontal pockets in the whole mouth. ${ }^{10}$ It has been demonstrated that salivary biomarkers which are closely related to periodontal disease are correlated with clinical parameters of periodontitis. ${ }^{11}$ Therefore, the biochemical analyses of salivary proteins may be useful for the development of the the saliva-based diagnostic test for periodontal disease..$^{10,11}$ To the best of our knowledge, there is a limited data on the salivary resistin levels in systemically healthy periodontitis patients. ${ }^{12,13}$ Considering the increased salivary resistin levels in chronic periodontitis patients in these recent studies, additional studies are needed to validate the diagnostic capacity of salivary levels of this molecule in periodontal diseases. Therefore, the aim of the present study was to evaluate the salivary resistin profile in a wide range of periodontal condition from periodontal health to gingivitis, chronic and aggressive forms of periodontitis, concurrently, in systemically healthy individuals as well as its correlations with clinical periodontal parameters and TNF- $\alpha$.

\section{Materials\&Methods}

\section{Study Population and Clinical Examination}

A total of 80 individuals (42 females and 38 males; age range $27-55$ years) seeking dental treatment in the School of Dentistry, Adnan Menderes University, Aydin, Turkey, were recruited for the present study from June to December of 2017. The protocol was approved by the Ethics Committee of the School of Medicine, Ege University with the protocol number (No: 17-3/18) and the research was conducted in compliance with the Declaration of Helsinki (version 2008). The purpose and procedures of the study were explained and written informed consent was received from each participant prior to participation. A detailed medical and dental history were taken from each participant with an oral examination. Inclusion criteria included: 1) aged 20 to 60 years 2) non-smokers with no history of smoking 3 ) having at least 16 remaining teeth. 4 ) having body mass index that is in the range of 18.5 to $24.9 \mathrm{~kg} / \mathrm{m}^{2}$. Exclusion criteria were as follows: 1) having any diagnosed medical disorders such as diabetes mellitus, cardiovascular diseases, rheumatoid arthritis, immunological and mucocutaneous diseases 2) having salivary gland dysfunction 3) usage of antibiotics, non-steroidal antiinflammatory drugs and immunosuppressive agents within the past 6 months 3 ) having any non-inflammatory destructive periodontal disease 4) nonsurgical/surgical periodontal therapy received in the past year 5) having a restorative and endodontic treatment requirement 6) having orthodontic appliances or a removable partial denture 7) current pregnancy or lactation.

Whole-mouth clinical periodontal measurements including probing pocket depth (PD), clinical attachment level (CAL), papilla bleeding index $(\mathrm{PBI})^{14}$, the percentage of sites with bleeding on probing (BOP \%) and plaque index $(\mathrm{PI})^{15}$ were recorded for each subject by a single trained calibrated examiner (BA). PD and 
CAL were measured in millimeter at 6 sites per tooth, except the third molars, using a manual periodontal probe (William's periodontal probe, Hu-Friedy, Chicago, IL). Periodontal depth was defined as the distance between the gingival margin and the bottom of periodontal pocket. The cemento-enamel junction used as a fixed reference point for the measurement of CAL. The alveolar bone resorption was assessed on the digital panoramic radiograph in each participant, which was supplemented with periapical radiographs if necessary.

According to the diagnostic criteria proposed by the 1999 International Workshop for a Classification of Periodontal Diseases and Conditions ${ }^{16}$, participants were categorized into four distinct groups based upon their periodontal status: 1) 20 patients with generalized aggressive periodontitis (G-AgP) 2) 20 patients with chronic periodontitis (CP) 3) 20 patients with gingivitis 4) 20 periodontally healthy individuals. The patients with G-AgP group had a minimum of CAL $\geq 5 \mathrm{~mm}$ and $\mathrm{PD} \geq 6$ $\mathrm{mm}$ on eight or more teeth; at least three of these were other than central incisors of first molars. Radiographic alveolar bone loss was $\geq 30 \%$ of root length affecting $\geq 3$ permanent teeth other than first molars and incisors. This generalized pattern of severe destruction was inconsistent with the amount of plaque accumulation or local risk factors. The patients with CP had minimum of four nonadjacent teeth with sites with $\mathrm{CAL} \geq 5 \mathrm{~mm}$ and $\mathrm{PD} \geq 6$ $\mathrm{mm}$. They had also $\geq 50 \%$ alveolar bone loss in at least two quadrants which was compatible with the amount of microbial deposits. Gingivitis patients had varying degrees of gingival inflammation. BOP was $>50 \%$ in the whole mouth. They exhibited no sites with CAL $>2 \mathrm{~mm}$ and no detectable alveolar bone loss in the radiography. Periodontally healthy individuals in the control group had no sites with PD $>3 \mathrm{~mm}$ and CAL $>2 \mathrm{~mm}$ and also no radiographic evidence of alveolar bone loss. BOP was $<15 \%$ in the whole mouth.

\section{Saliva Collection}

Saliva was collected by means of a modification of the method described by Navazesh. ${ }^{17}$ Prior tho clinical evaluation, unstimulated whole saliva obtained from the patients in the morning between 8:30 am-10:30 am after an overnight fast. The participants were asked to avoid drinking (except water), oral care practices (brushing, interdental cleaning and rinsing with mouthwash) or chewing gum. While seated in an upright position, each participant were requested to swallow any residual saliva and then to let the saliva pool in their floor of the mouth to their maximum extent. They were instructed to allow the saliva to drain passively into a sterile plastic container over the lower lip for 5 minute. Saliva samples were held on ice and then stored at $-80^{\circ} \mathrm{C}$, until the analysis.

\section{Measurement of Resistin and TNF- $\alpha$ Levels in Saliva Samples}

Frozen saliva samples were thawed on ice and centrifuged at $10000 \mathrm{x}$ g for 15 minutes at $4{ }^{\circ} \mathrm{C}$ on the day of analysis. Salivary resistin and TNF- $\alpha$ values were obtained by using commercial ELISA kits (Human Resistin and TNF- $\alpha$ ELISA kits, Sunred Biotechnology, Shanghai). The minimum detection limits in the assays were $0.25 \mathrm{ng} / \mathrm{mL}$ for resistin and $2.82 \mathrm{ng} / \mathrm{L}$ for TNF- $\alpha$. The optical density was measured by absorbance microplate reader (ELx800, BioTek Instruments, Vermont) at 450 $\mathrm{nm}$ with a reference wavelength of 620-650 nm. Cytokine concentrations in samples were calculated according to standard curve. Salivary concentrations of resistin and $\mathrm{TNF}-\alpha$ were detected as $\mathrm{ng} / \mathrm{mL}$ and $\mathrm{ng} / \mathrm{L}$, repectively.

\section{Statistical Analysis}

The sample size was calculated using a specialized software package ( $\mathrm{G}^{*}$ Power version 3.0.8, Heinrich Heine University, Düsseldorf) for power analysis. The analysis revealed that 19 participants per group would be required to detect statistical significance among four groups at 0.40 f-type effect size, 0.05 type I error, and $80 \%$ power under One-Way ANOVA method.

All the statistical calculations were carried out using a statistical software package (GraphPad Prisim version 8.0.0 for Windows, GraphPad Software, San Diego, CA, USA). Normality of the data was checked by D'AgostinoPearson omnibus normality test. The differences among groups were assessed with Kruskal-Wallis test, and Dunn's test was used to correct for multiple pairwise comparisons for non-normally distributed variables (resistin and TNF- $\alpha$ levels in saliva). One-way ANOVA test with Holm-Sidak's multiple comparison test was used for normally distributed variables (age, PD, CAL, PI, $\mathrm{PBI}$ and BOP). Correlations between clinical parameters and biomarker levels were assessed by Spearman's correlation test. Statistical significance was considered at $\mathrm{p}<0.05$ for all the tests.

\section{Results}

The demographic characteristics and whole mouth clinical periodontal parameters are presented in Table 1. CP group had significantly higher mean age value than G-AgP, gingivitis and healthy groups $(\mathrm{P}<0.05)$. 
There was no statistical difference in age among G-AgP, gingivitis and healthy groups $(\mathrm{P}>0.05)$. No significant differences were observed in gender distrubition and BMI values among the study groups $(\mathrm{P}>0.05)$. G-AgP, $\mathrm{CP}$ and gingivitis groups had significantly higher mean $\mathrm{PD}$ and CAL scores compared to healthy group $(p<0.05)$. These groups had also significantly higher mean PI, PBI and BOP $(\%)$ values compared to healthy group $(p<0.0001)$.
Both periodontitis groups had significantly higher mean $\mathrm{PD}, \mathrm{CAL}, \mathrm{PBI}$ and BOP (\%) values compared to gingivitis group ( $\mathrm{p}<0.0001)$. While $\mathrm{G}-\mathrm{AgP}$ group had significantly higher mean PI scores than gingivitis group $(p<0.05)$, there were no significant differences between $\mathrm{CP}$ and gingivitis groups $(\mathrm{P}>0.05)$. $\mathrm{G}-\mathrm{AgP}$ and $\mathrm{CP}$ groups had similar mean PD, CAL, PI, PBI and BOP (\%) values ( $\mathrm{p}$ $>0.05)$.

Table 1. The demographic characteristics and whole-mouth clinical periodontal parameters of the study groups.

\begin{tabular}{lllll}
\hline & $\begin{array}{l}\text { G-AgP } \\
(\mathrm{n}=20)\end{array}$ & $\begin{array}{l}\text { CP } \\
(\mathrm{n}=20)\end{array}$ & $\begin{array}{l}\text { Gingivitis } \\
(\mathrm{n}=20)\end{array}$ & $\begin{array}{l}\text { Health } \\
(\mathrm{n}=20)\end{array}$ \\
\hline Demographic variables & & & & $37.30 \pm 4.54$ \\
Age (years) & $38.35 \pm 5.01$ & $48.35 \pm 5.10^{*}$ & $36.20 \pm 5.00$ & $10 / 10$ \\
Sex (Female / Male) & $12 / 8$ & $9 / 11$ & $12 / 8$ & $22.67 \pm 0.93$ \\
BMI $\left(\mathrm{kg} / \mathrm{m}^{2}\right)$ & $22.78 \pm 1.34$ & $23.64 \pm 1.27$ & $23.25 \pm 1.28$ & $1.74 \pm 0.21^{*}$ \\
Periodontal parameters & & & & $1.78 \pm 0.20^{*}$ \\
PD (mm) & $4.30 \pm 0.72$ & $4.16 \pm 0.51$ & $2.19 \pm 0.27^{\dagger}$ & $0.15 \pm 0.12^{*}$ \\
CAL (mm) & $5.10 \pm 0.86$ & $5.04 \pm 0.66$ & $2.22 \pm 0.26^{\dagger}$ & $2.22 \pm 0.47^{\dagger}$ \\
PBI & $2.88 \pm 0.55$ & $2.83 \pm 0.51$ & $66.02 \pm 6.33^{\dagger}$ & $1.87 \pm 1.06^{*}$ \\
BOP $(\%)$ & $86.13 \pm 6.11$ & $84.50 \pm 7.24$ & $3.08 \pm 0.63^{*}$ & $1.71 \pm 0.41^{*}$ \\
PI & $3.62 \pm 0.71$ & $3.42 \pm 0.47$ & & \\
\hline
\end{tabular}

All data (except forsex) are given as mean \pm SD. $* \mathrm{p}<0.05$, significant difference from othergroups. ${ }^{\dagger} \mathrm{p}<0.05$, significant difference from G-AgP and CP. ${ }^{*} \mathrm{p}<0.05$, significant difference from G-AgP. G-AgP: Generalized aggressive periodontitis, CP: Chronic periodontitis; PD: Probing pocket depth, CAL: Clinical attachment level, PBI: Papillary bleeding index, BOP: Bleeding on probing, PI: Plaque index.

Figure 1 presents salivary resistin concentrations (ng/mL) of the studied groups. Resistin was detected in all saliva samples. Although G-AgP, CP and gingivitis groups had higher salivary resistin levels compared to healthy controls, this did not reach to significance ( $P$ $>0.05)$. G-AgP, CP and gingivitis groups had similar salivary resistin levels $(\mathrm{P}>0.05)$.

TNF- $\alpha$ concentrations (ng/L) of study groups were demonstrated Figure 2. TNF- $\alpha$ was also detected in all saliva samples. Regarding salivary TNF- $\alpha$ concentrations, there were no significant differences among study groups $(\mathrm{P}>0.05)$.

Salivary resistin and TNF- $\alpha$ concentrations showed no correlation with age and whole mouth clinical parameters $(\mathrm{P}>0.05$, Table 2$)$. There was a positive correlation between resistin and TNF- $\alpha$ levels in saliva ( $r=0.661, p<0.001$, Table 2).

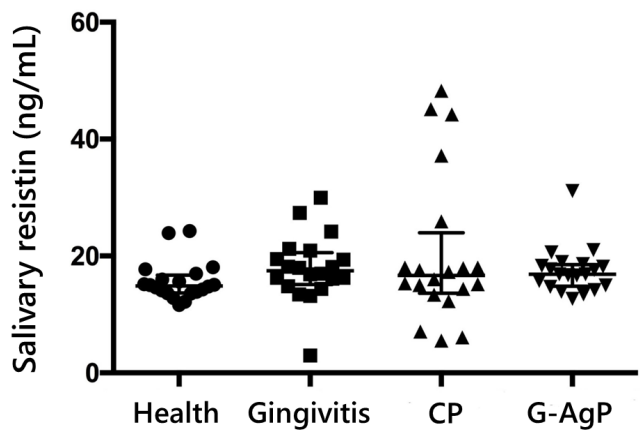

Figure 1: Saliva resistin levels $(\mathrm{ng} / \mathrm{mL})$ in Generalized Aggressive Periodontitis (G-AgP), generalized chronic periodontitis (CP), gingivitis and in periodontal health. The horizontal lines in the box blots represent the median values, and the whiskers represent the 5 to 95 percentiles. Values below and above the whiskers are drawn as individuals dots. 
Table 2. Correlations of salivary resistin and TNF- $\alpha$ levels with clinical periodontal parameters and each others.

\begin{tabular}{cccc}
\hline Variables & & Resistin & TNF- $\alpha$ \\
\hline Age & r & -0.028 & -0.047 \\
PD & r & 0.094 & 0.108 \\
CAL & r & 0.092 & 0.116 \\
PBI & r & 0.174 & 0.135 \\
PI & r & 0.087 & 0.055 \\
Resistin & r & & $\mathbf{0 . 6 6 1}$ \\
TNF- $\alpha$ & r & $\mathbf{0 . 6 6 1}$ & \\
\hline
\end{tabular}

Significant correlations are shown in bold face. Correlation is significant at the 0.01 level. PD: Probing pocket depth, CAL: Clinical attachment level, PBI: Papillary bleeding index, PI: Plaque index, TNF- $\alpha$ : Tumor necrosis factor- $\alpha$.

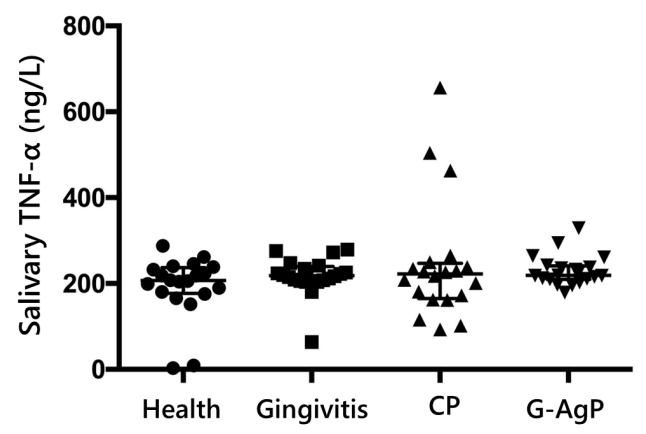

Figure 2: Saliva TNF- $\alpha$ levels (ng/L) in Generalized Aggressive Periodontitis (G-AgP), generalized chronic periodontitis (CP), gingivitis and in periodontal health. The horizontal lines in the box blots represent the median values, and the whiskers represent the 5 to 95 percentiles. Values below and above the whiskers are drawn as individuals dots.

\section{Discussion}

Resistin is a pro-inflammatory cytokine released by adipocytes and immunoinflammatory cells, indicating its role in numerous chronic inflammatory diseases. ${ }^{4,5}$ The present cross-sectional study comparatively evaluated the salivary levels of resistin and TNF- $\alpha$ in patients with different periodontal diseases to determine how these levels regulate with the increased severity of periodontal disease. To the best of our knowledge, this is the first study evaluating salivary resistin levels, concurrently, in chronic and aggressive form of periodontitis, gingivitis and periodontally health.

To date, there are a limited data about the salivary levels of resistin in chronic periodontitis patients..$^{12,13,18,19}$
Esfahrood et al. ${ }^{12}$ reported that chronic periodontitis patients had significantly higher salivary resistin levels than the periodontally healthy subjects. Al-Hamoudi et al. ${ }^{13}$ and Akram et al. ${ }^{18}$ demonstrated that salivary resistin levels decreased after non-surgical periodontal treatment in obese patients with chronic periodontitis. Al-Rawi et al. ${ }^{19}$ suggested that elevated salivary levels of periodontal pathogens could upregulate the local release of resistin in saliva of obese individuals with mild form of periodontal disease. It has been known that human resistin is primarily expressed by immunoinflammatory cells such as monocytes and macrophages and also epithelial cells. ${ }^{4,5}$ In vitro studies demonstrated that lipopolysaccharide from Porphyromonas gingivalis, a major pathogen of periodontitis, causes resistin release from human neutrophil. ${ }^{8}$ In periodontitis patients, increased inflammatory cell infiltration ${ }^{7-9}$ and also lipopolysaccharide-induced proinflammatory cytokine expression (such as TNF- $\alpha$ and IL-6) may lead to increased salivary resistin levels. ${ }^{6,20}$ In contrary, in the current study, salivary resistin levels in periodontitis groups were similar to those of periodontally healthy control. One possible explanation for the discrepancy between the findings of the previous studies ${ }^{12,13,18,19}$ and those of the present study may be the differences in patient selection method and sampling methods. The present study was conducted in systemically healthy individuals with normal weight suffering from severe chronic periodontitis however, the severity of disease and body mass index values of selected study population are unclear in the study by Esfahrood et al. ${ }^{12}$ which can affect salivary resistin levels. 
In the present study gingivitis group allowed us to compare how resistin and TNF- $\alpha$ are involved in the destructive process during the periodontal disease progression. Furugen et al. ${ }^{7}$ showed serum resistin levels to be strongly correlated with bleeding on probing, a clinical sign of periodontal inflammation, rather than PD. In the present study although gingivitis group has significantly lower PBI scores compared to diseased groups, while had higher scores than the healthy group, salivary resistin levels were similar among groups. In other words, salivary resistin levels lacked the ability to distinguish gingivitis from health or periodontitis.

Aggressive periodontitis can be distinguished from chronic periodontitis by the relatively early age of onset, high rate of disease progression, clinical appearance and familial predisposition. ${ }^{16}$ Differences in host response and biochemical diversity may help to differentiate G-AgP and CP. ${ }^{21}$ However, present findings revealed that salivary resistin and TNF- $\alpha$ levels could not differentiate G-AgP from CP patients, which presented similar clinical periodontal parameters. The transcriptomic analysis of gingival tissue also revealed that $\mathrm{G}-\mathrm{AgP}$ is comparable to $\mathrm{CP}$ at the molecular level. ${ }^{22}$ Further mechanistic studies will provide more information about the role of resistin in these two main forms of periodontitis.

The present findings revealed that the salivary resistin levels were not correlated with the clinical periodontal parameters of periodontal disease. Akram et al. ${ }^{18}$ reported that decrease in salivary resistin levels after non-surgical periodontal treatment in obese patients with chronic periodontitis was not associated with improvement in periodontal parameters. On the other hand, several studies on GCF levels of resistin in chronic periodontitis patients reported positive correlation between resistin and clinical periodontal parameters. ${ }^{8,9}$ Although it has been speculated that GCF is the primary source of periodontitis-associated cytokines in whole saliva ${ }^{3,10}$, individual variations in the diluation of GCF components or unknown inhibitory factors in whole saliva may mask existing differences in the levels of these cytokines in different periodontal status at the site levels. ${ }^{10,11}$ It is well-known that saliva, a unique oral fluid, composed of secretions from the major and minor salivary glands, GCF, nasal and bronchial secretions, microbes and microbial metabolites, blood cells and serum derivates from oral wounds desquamated epithelial cells and food remnants. ${ }^{10}$ As GCF resistin levels were not measured in the current study, no judgement could be made on this point. Further studies including more detailed protocols and advanced technical procedures are needed to determine the source of resistin and TNF- $\alpha$ in whole saliva.

There are conflicting results regarding salivary TNF- $\alpha$ levels in patients with periodontal disease which is a potential marker of periodontal inflammation. ${ }^{23,24}$ Elevated salivary TNF- $\alpha$ levels were found in G-AgP and CP patients. ${ }^{23,25}$ In contrary, similar to our findings, previous studies ${ }^{24,26}$ have reported that no relationship was found between the salivary TNF- $\alpha$ concentration and periodontal inflammation. The discrepancies between the findings of previous studies ${ }^{23,25}$ and those of the present study could be attributed to variations in the severity of periodontal disease and smoking history in selected study populations.

In the present study, there were strong positive correlations between resistin and TNF- $\alpha$ levels in saliva. This finding may provide further support for the previous studies reporting resistin stimulates the secretion of TNF- $\alpha$, IL-6 and IL-12 through NF-kB pathway ${ }^{4,6}$ and also it is induced by lipopolysaccharide, TNF- $\alpha$, or IL$6.8,20$

The present study has some limitations that should be considered. The cross-sectional nature of this study limits its ability to make causal relationship between biomarkers evaluated and periodontal status. Age could be a potential confounding variable in the interpretation of the present findings due to the imperfectly agematched individuals in $\mathrm{CP}$ and other groups. However, no significant correlations were found between age and biomarker levels in this study. Another limitation may be the lack of GCF analysis. The levels of the resistin and TNF- $\alpha$ in GCF may be useful in understanding the role of these markers in periodontal disease and the source of these markers in whole saliva.

\section{Conclusions}

Within the limitations of this study, it can be suggested that the salivary resistin and TNF- $\alpha$ levels can not differentiate periodontal disease from health. Further studies including more detailed protocols and advanced technical procedures may serve to elucidate the source of resistin and TNF- $\alpha$ in whole saliva and also the role of these biomarkers in the periodontal inflammation. 


\section{References}

1. Socransky SS, Haffajee AD, Cugini MA, Smith C, Kent RL Jr. Microbial complexes in subgingival plaque. J Clin Periodontol 1998;25:134-144.

2. Cekici A, Kantarci A, Hasturk H, Van Dyke TE. Inflammatory and immune pathways in the pathogenesis of periodontal disease. Periodontol 2000 2014;64:57-80.

3. Buduneli N, Kinane DF. Host-derived diagnostic markers related to soft tissue destruction and bone degradation in periodontitis. $J$ Clin Periodontol 2011;38 Suppl 11:85-105.

4. Bokarewa M, Nagaev I, Dahlberg L, Smith U, Tarkowski A. Resistin, an adipokine with potent proinflammatory properties. J Immunol 2005; 174:5789-5795.

5. Park HK, Ahima RS. Resistin in rodents and humans. Diabetes Metab J 2013;37:404-414.

6. Silswal N, Singh AK, Aruna B et al. Human resistin stimulates the pro-inflammatory cytokines TNF- $\alpha$ and IL-12 in macrophages by NF- $\kappa$ Bdependent pathway. Biochem Biophys Res Commun 2005;334:1092-1101.

7. Furugen R, Hayashida H, Yamaguchi $\mathrm{N}$ et al. The relationship between periodontal condition and serum levels of resistin and adiponectin in elderly Japanese. J Periodontal Res 2008;43:556-562.

8. Hiroshima Y, Bando M, Inagaki Y et al. Resistin in gingival crevicular fluid and induction of resistin release by Porphyromonas gingivalis lipopolysaccharide in human neutrophils. $J$ Periodontal Res 2012;47:554-562.

9. Gokhale NH, Acharya AB, Patil VS et al. Resistin levels in gingival crevicular fluid of patients with chronic periodontitis and type 2 diabetes mellitus. J Periodontol 2014;85:610-617.

10. Jaedicke KM, Preshaw PM, Taylor JJ. Salivary cytokines as biomarkers of periodontal diseases. Periodontol 2000 2016;70:164-183.

11. Ghallab NA. Diagnostic potential and future directions of biomarkers in gingival crevicular fluid and saliva of periodontal diseases: Review of the current evidence. Arch Oral Biol 2018;87:115-124.
12. Esfahrood ZR, Tehrani VS, Yadegari $Z$ et al. Evaluation of Resistin Levels in Saliva of Patients with Chronic Periodontitis and Healthy Subjects. Chin J Dent Res 2018;21:143-146.

13. Al-Hamoudi N, Abduljabbar T, Mirza S et al. Non-surgical periodontal therapy reduces salivary adipocytokines in chronic periodontitis patients with and without obesity. J Investig Clin Dent 2018 May;9:e12314.

14. Newbrun E. Indices to measure gingival bleeding. $J$ Periodontol 1996;67:555-561.

15. Quigley GA, Hein JW. Comparative cleansing efficiency of manual and power brushing. J Am Dent Assoc 1962;65:26-29.

16. Armitage GC. Development of a classification system for periodontal diseases and conditions. Ann Periodontol 1999;4:1-6

17. Navazesh M. Methods for collecting saliva. Ann N Y Acad Sci 1993;694:72-77.

18. Akram Z, Baharuddin NA, Vaithilingam RD et al. Effect of nonsurgical periodontal treatment on clinical periodontal variables and salivary resistin levels in obese Asians. J Oral Sci 2017;59:93-102.

19. Al-Rawi N, Al-Marzooq F. The Relation between Periodontopathogenic Bacterial Levels and Resistin in the Saliva of Obese Type 2 Diabetic Patients. J Diabetes Res 2017;2017:2643079.

20. Kaser S, Kaser A, Sandhofer A et al. Resistin messenger-RNA expression is increased by proinflammatory cytokines in vitro. Biochem Biophys Res Commun 2003;19:286-290.

21. Smith M, Seymour GJ, Cullinan MP. Histopathological features of chronic and aggressive periodontitis. Periodontol 2000 2010;53:45-54.

22. Kebschull M, Demmer RT, Grün B et al. Gingival tissue transcriptomes identify distinct periodontitis phenotypes. J Dent Res 2014;93:459-468.

23. Frodge BD, Ebersole JL, Kryscio RJ, Thomas $\mathrm{MV}$, Miller CS. Bone remodeling biomarkers of periodontal disease in saliva. $J$ Periodontol 2008;79:1913-9.

24. Teles RP, Likhari V, Socransky SS, Haffajee AD. Salivary cytokine levels in subjects with 
chronic periodontitis and in periodontally healthy individuals: a cross-sectional study. J Periodontal Res 2009;44:411-417.

25. Gümüș P, Nizam N, Lappin DF, Buduneli N. Saliva and serum levels of B-cell activating factors and tumor necrosis factor- $\alpha$ in patients with periodontitis. J Periodontol 2014;85:270-280.

26. Ebersole JL, Schuster JL, Stevens J et al. Patterns of salivary analytes provide diagnostic capacity for distinguishing chronic adultperiodontitis fromhealth. J Clin Immunol 2013;33:271-279. 